\title{
Teste intradérmico com proteínas recombinantes de Mycobacterium bovis como antígenos em Cavia porcellus ${ }^{1}$
}

\author{
Elaine S.P. Melo²*, Ingrid I.F. Souza², Carlos A.N. Ramos ${ }^{3}$, Ana Luíza A.R. Osório², \\ Valter A. Nascimento ${ }^{4}$ e Flábio R. Araújo ${ }^{5}$
}

\begin{abstract}
Melo E.S.P., Souza I.I.F., Ramos C.A.N., Osório A.L.A.R., Nascimento V.A. \& Araújo F.R. 2014. [Skin test with recombinant protein of Mycobacterium bovis as antigen in Cavia porcellus.] Teste intradérmico com proteínas recombinantes de Mycobacterium bovis como antígenos em Cavia porcellus. Pesquisa Veterinária Brasileira 34(10):957-962. Programa de Pós-Graduação em Ciência Animal, Faculdade de Medicina Veterinária, Universidade Federal de Mato Grosso do Sul, Av. Senador Filinto Mülller 2443, Cidade Universitária, Campo Grande, MS 79070-900, Brazil. E-mail: elainespmelo@hotmail.com

The intradermal skin test for diagnosis of bovine tuberculosis has been used the purified protein derivative (PPD) of Mycobacterium bovis, that is able to induce a hypersensitivity reaction in infected animals. However, shows low specificity due to the occurrence of cross reactions with other mycobacteria. Thus, the aim of this study was to produce recombinant proteins (ESAT-6, PE13, PE5 and ESX-1) of Mycobacterium bovis and assess them as antigens in skin test using guinea pigs (Cavia porcellus) as a model, and check if the conditions employed in the purification (native or denaturing condition) interfere in the antigenic performance of these proteins. The proteins were tested in guinea pigs previously sensitized with inactivated $M$. bovis strain AN5, individually $(160 \mu \mathrm{g} / \mu \mathrm{l})$, or as a mixed cocktail ( $40 \mu \mathrm{g}$ each). The cocktail of proteins induced hypersensitivity reactions in sensitized animals significantly $(p=0.002)$ higher than those observed in non-sensitized animals, allowing differentiation. On the other hand, the proteins individually were not able to promote this differentiation. The conditions of solubilization and purification influenced the antigenic performance of the protein ESAT-6, since, when produced in denaturing condition triggered nonspecific reaction in non-sensitized animals. Whereas when produced under native conditions and used at concentrations $(6,12,24$ and $48 \mu \mathrm{g} / \mu \mathrm{l})$ induced a significant response only in sensitized animals, confirming its potential as antigen.
\end{abstract}

INDEX TERMS: Bovine PPD, skin test, bovine tuberculosis, Mycobacterium bovis, solubility cattle.

RESUMO.- 0 teste intradérmico para o diagnóstico da tuberculose bovina utiliza derivados proteicos purificados (PPD) de Mycobacterium bovis que são capazes de induzir reações de hipersensibilidade em animais infectados. No

\footnotetext{
${ }^{1}$ Recebido em 17 de março de 2014.

Aceito para publicação em 28 de agosto de 2014.

${ }^{2}$ Programa de Pós-Graduação em Ciência Animal, Faculdade de Medicina Veterinária (Famez), Universidade Federal de Mato Grosso do Sul (UFMS), Avenida Senador Filinto Müller 2443, Cidade Universitária, Campo Grande, MS 79070-900, Brasil. *Autor para correspondência: elainespmelo @hotmail.com

${ }^{3}$ Laboratório de Biologia Molecular, FAMEZ/UFMS, Av. Filinto Muller 2443, Cidade Universitária, Campo Grande, MS 70106-550.

${ }^{4}$ Programa de Pós-Graduação em Saúdee Desenvolvimentona RegiãoCentro-Oeste, Faculdade de Medicina, UFMS, Campo Grande, MS 79070-900.

${ }^{5}$ Laboratório de Imunologia, Sanidade Animal, Embrapa Gado de Corte, Av. Rádio Maia 830, Zona Rural, Campo Grande, MS 70106-550.
}

entanto, apresenta baixa especificidade devido à ocorrência de reações cruzadas com outras micobactérias. Neste sentido, o objetivo desse trabalho foi produzir proteínas recombinantes (ESAT-6, PE13, PE5 e ESX-1) de Mycobacterium bovis e avaliá-las como antígenos em teste intradérmico utilizando Cavia porcellus como modelo, e verificar se as condições empregadas na purificação (nativa ou desnaturante) interferem no desempenho antigênico dessas proteínas. As proteínas foram testadas em Cavia porcellus previamente sensibilizados com cepa $M$. bovis AN5 inativada, individualmente $(160 \mu \mathrm{g})$ ou combinadas na forma de um coquetel ( $40 \mu$ g cada). 0 coquetel de proteínas induziu reações de hipersensibilidade nos animais sensibilizados significativamente superiores $(\mathrm{p}=0,002)$ as observadas nos animais não sensibilizados, possibilitando diferenciação. No entanto, as proteínas isoladamente não foram capazes 
de promover essa diferenciação. As condições de solubilização e purificação influenciaram o desempenho antigênico da proteína ESAT-6, pois, quando produzida em condição desnaturante desencadeou reações inespecíficas nos animais não sensibilizados, enquanto que aquela produzida em condições nativas e aplicada em concentrações de $6,12,24$ e $48 \mu$ g induziu reações significativas apenas nos animais sensibilizados, confirmando o seu potencial como antígeno.

TERMOS DE INDEXAÇÃO: PPD bovino, teste intradérmico, tuberculose bovina, Mycobacterium bovis, solubilidade, bovinos.

\section{INTRODUÇÃO}

A tuberculose bovina é uma doença infecciosa de importância zoonótica, distribuída globalmente e causada principalmente pela bactéria Mycobacterium bovis (Michel et al. 2010). Essa enfermidade representa impacto negativo na cadeia produtiva da carne devido aos prejuízos econômicos vinculados à redução gradativa dos índices zootécnicos (Boland et al. 2010). Além disso, torna os produtos provenientes da pecuária vulneráveis as barreiras sanitárias impostas pelo mercado internacional (Michel et al. 2010).

Não existe uma vacina eficaz para a tuberculose bovina (OIE 2013) e os programas de controle e erradicação da enfermidade realizados na maioria dos países (Álvarez et al. 2012) inclusive no Brasil (Programa Nacional de Controle e Erradicação da Brucelose e Tuberculose Animal-PNCEBT), são baseados no método tradicional de diagnóstico, o teste intradérmico, que visa a detecção de uma reação de hipersensibilidade tardia (DTH) induzida após a inoculação de derivado proteico purificado (PPD), que gera uma reação inflamatória local nos animais com infecção prévia pelo bacilo (Xin et al. 2013).

O PPD utilizado no teste é composto por uma mistura complexa de proteínas e outros compostos solúveis em água, provenientes da cultura de M. bovis (Vutla et al. 2011). Podem ser utilizados dois tipos de PPD: o PPD bovino que corresponde ao extrato antigênico de proteínas purificadas, derivadas de M. bovis cepa AN5 utilizada no teste cervical simples (TCS) e no teste da prega caudal (TPC); e o PPD aviário, purificado a partir de M. avium cepa D4, que em conjunto com o PPD bovino, pode ser utilizado no teste cervical comparativo (TCC) (Brasil 2006). No entanto, o teste intradérmico simples pode apresentar problemas relativos à especificidade devido às reações cruzadas com outras espécies de micobactérias, bem como a fatores inerentes ao hospedeiro (Álvarez et al. 2012). Dessa forma, torna-se necessária a realização de teste comparativo em reações inconclusivas, o que torna o diagnóstico mais demorado e com custos mais elevados (Schiller et al. 2010). Pois, os animais reagentes e inconclusivos só podem ser retestados no teste intradérmico cervical comparativo após um intervalo de 60 a 90 dias, ou podem ser considerados positivos e destinados ao abate sanitário (Brasil 2006). Este intervalo mínimo para repetição do teste visa evitar a ocorrência de resultados falso-negativos, uma vez que após o teste cutâneo pode ocorrer a dessensibilização do animal, estado no qual há uma diminuição na capacidade de responder a no- vos testes (Buddle et al. 2009). Dessa forma, testes diagnósticos sensíveis e mais específicos são necessários para o avanço na estratégia de controle em direção à erradicação da tuberculose bovina (Menin et al. 2013).

Diversos antígenos, principalmente aqueles envolvidos na resposta imune celular e humoral do hospedeiro, como as proteínas ESAT-6, CFP10, MPB70, MPB83 e RV3615c, têm sido propostos para utilização em diagnóstico da tuberculose bovina e humana, seja em teste intradérmico ou quantificação de interferon- $\gamma$ (Kalra et al. 2010, Whelan et al. 2010, Flores-Villalva et al. 2012). A proposta neste estudo foi produzir as proteínas recombinantes PE5, PE13, ESAT-6 e ESX-1 de $M$. bovis, envolvidas na resposta imune celular dos bovinos, avaliá-las como antígenos em teste intradérmico utilizando Cavia porcellus como modelo, e verificar se as condições empregadas na purificação (condições nativas ou desnaturantes) interferem no desempenho antigênico dessas proteínas.

\section{MATERIAL E MÉTODOS}

Amplificação dos genes. Os genes pe5, pe13 e esat-6 foram amplificados por reação em cadeia da polimerase (PCR) a partir de DNA de $M$. bovis cepa AN5, utilizando oligonucleotídeos iniciadores específicos desenhados e amplificados de acordo com Souza et al. (2012). 0 gene esx-1 foi amplificado com os primers (forward: 5' TATCAATTCGGGGACGTCGACGCTCACG 3' e reverse: 5' GGCGCTGTCGGTTTGTGCCATGTTGTTG 3') desenhados utilizando o programa PrimerSelect (DNASTAR).

Clonagem dos genes e produção das proteínas recombinantes. Os genes amplificados foram clonados em plasmídeo pGEM-T Easy (Promega), seguindo as instruções do fabricante e subclonados em plasmídeo $p E T 47 b$ (Novagen). A indução da expressão dos genes em Escherichia coli Rosetta foi realizada utilizando $1 \mathrm{mM} / \mathrm{ml}$ de isopropil- $\beta$-D-galactopiranosideo (IPTG) em $500 \mathrm{ml}$ de Luria-Bertani caldo contendo $50 \mu \mathrm{g} / \mathrm{ml}$ de cloranfenicol e $30 \mu \mathrm{g} / \mathrm{ml}$ de canamicina, a $30^{\circ} \mathrm{C}$ durante $4 \mathrm{~h}$ a $200 \mathrm{rpm}$. A expressão dos genes foi confirmada por eletroforese em gel de poliacrilamida (12\%) em condições desnaturantes (SDS-PAGE) e Western-blot com anticorpo monoclonal anti-6x-histidina (Sigma).

As suspensões bacterianas foram centrifugadas a $10.000 \mathrm{xg}$ por 10 minutos e os sedimentos ressuspensos em tampão contendo n-lauril-sarcosil e triton X-100, ambos a $1 \%$ e incubados por uma hora em banho-maria a $37^{\circ} \mathrm{C}$. A solução foi submetida à desrupção ultrassônica seis vezes por 10 segundos e centrifugada conforme descrita anteriormente. As proteínas foram purificadas por cromatografia de afinidade em resina de agarose-níquel utilizando as colunas de cromatografia His-trap HP (GE Healthcare) em condições nativas, ou seja, sem a utilização de agentes desnaturantes, seguindo as instruções do fabricante. Após purificação as proteínas foram dialisadas em tampão fosfato a $4^{\circ} \mathrm{C}$ por 72 horas, quantificadas por fluorometria em sistema Qubit (Invitrogen) e a purificação confirmada por SDS-PAGE.

Uma alíquota do sedimento de cultura de ESAT-6 também foi ressuspensa em tampão de lise $\left(\mathrm{Na}_{2} \mathrm{HPO}_{4} 20 \mathrm{mM}\right.$; $\mathrm{NaCl}$ 0,5 M; guanidina $\mathrm{HCl} 6 \mathrm{M}$ ) pH 8,0 e incubada por uma hora em banho-maria a $37^{\circ} \mathrm{C}$. A purificação foi realizada utilizando o mesmo sistema de cromatografia descrito acima, mas em condições desnaturantes, empregando uréia (8 M) nos tampões de lavagem e eluição. Após a purificação, a proteína foi dialisada e quantificada conforme descrito anteriormente.

Aspectos éticos. 0 uso de Cavia porcellus foi aprovado pelo Comitê de Ética no Uso de Animais da Universidade Federal de 
Mato Grosso do Sul, Brasil (protocolo 321/11). 0 experimento foi realizado em conformidade com as normas e regulamentos internacionais para experimentação com animais.

Sensibilização com Mycobacterium bovis. Vinte e oito fêmeas da espécie Cavia porcellus, pesando entre 250 e $350 \mathrm{~g}$, foram utilizadas nesse estudo. Os animais foram mantidos com ração comercial (Nuvilab) e água ad libitum, em ambiente com ciclo claro/ escuro controlado. Dezenove animais foram sensibilizados com M. bovis cepa AN5 (LANAGRO-MAPA, Brasil) inativada por calor (2 $\mathrm{mg} / \mathrm{ml}$ ) via intramuscular, na face interna da coxa direita, e nove animais receberam salina estéril e foram mantidos como controle negativo. Sete semanas após a sensibilização foi realizado o teste intradérmico.

Cavia porcellus foi utilizado como modelo nesse experimento devido ao fato de ser a espécie recomendada pela Organização Mundial de Saúde Animal (OIE) para a avaliação de potência do PPD produzido e comercializado (OIE, 2013).

Teste intradérmico. Todos os animais foram tosqueados nas regiões intercostais e os sítios de inoculação distribuídos no sentido oral-caudal, nos flancos direito e esquerdo para realizar o teste intradérmico.

Dez animais, (7 sensibilizados e 3 não sensibilizados) foram utilizados para avaliar o desempenho das proteínas recombinantes em diferenciar animais sensibilizados com $M$. bovis de animais não sensibilizados (Fig.1). Sete sítios de injeção intradérmica foram utilizados em cada animal. Todas as proteínas purificadas em condições nativas (PE5, PE13, ESAT-6 e ESX-1) foram administradas na concentração de $160 \mu \mathrm{g} / \mu \mathrm{l}$ individualmente e como componente de um coquetel formado por $40 \mu \mathrm{g}$ de cada proteína (totalizando $160 \mu \mathrm{g}$ de concentração final). PPD bovino (TECPAR, Curitiba, Brasil) na concentração de $5 \mu \mathrm{g} / \mu \mathrm{l}$ e salina foram incluídos em cada teste.

Avaliação da influência das condições de purificação no desempenho antigênico das proteínas. Para verificar se as condições de purificação das proteínas influenciaram no seu desempenho em estimular reação de hipersensibilidade tardia foram utilizados 18 animais. Em seis animais sensibilizados e três não sensibilizados foram aplicadas injeções intradérmicas com a proteína ESAT-6 purificada em condições nativas, em diluição seriada de $6,12,24$ e $48 \mu \mathrm{g} / \mu \mathrm{l}$ e os outros seis animais sensibilizados e três não sensibilizados receberam a proteína ESAT-6 nas mesmas dosagens descritas acima, mas purificada em condições desnaturantes (Fig.1).

A posição dos inóculos foi alternada em cada animal para minimizar o efeito dos pontos de inoculação sobre as médias das reações e as leituras das reações (mm) foram realizadas com base na medida da reação após 24 horas da aplicação dos inóculos, conforme metodologia apresentada por OIE (2013).

0 inoculador e o leitor não tinham informações sobre os inóculos, com o objetivo de evitar qualquer interferência consciente ou não nos resultados do experimento.

Análise estatística. A diferença entre as reações médias nos animais não sensibilizados e sensibilizados foram avaliadas pelo teste $t$ de Student, com nível de significância de 5\%, e a magnitude da reação induzida por diferentes concentrações de proteína foram avaliadas pela análise de variância 1 fator.

\section{RESULTADOS}

A inoculação do PPD bovino provocou reações intradérmicas em todos os animais sensibilizados $(n=19)$, que variaram entre 15 a $21 \mathrm{~mm}$ e foram significativamente superiores $(p<0,0001)$ às observadas nos animais não sensibilizados $(n=9)$. Diferentemente das proteínas utilizadas individualmente ou em forma de coquetel, que geraram reação inespecífica nos animais não sensibilizados.

As proteínas PE5, PE13, ESAT-6 e ESX-1 purificadas em condições nativas $(160 \mu \mathrm{g})$, quando utilizadas isoladamente, não apresentaram reações médias significativamente superiores nos animais sensibilizados com relação aos não sensibilizados $(\mathrm{p}<0,05)$. Apesar de ESAT-6 ter apresentado a maior reação média ( $9,3 \mathrm{~mm})$ nos animais sensibilizados, também provocou reações $(7 \mathrm{~mm})$ inespecíficas relevantes nos animais não sensibilizados (Fig.2). Mas quando as proteínas foram combinadas na forma de coquetel, composto por $40 \mu \mathrm{g}$ de cada uma, elas foram capazes de diferenciar os animais sensibilizados dos não sensibilizados $(p=0,002)$.

0 teste intradérmico com a proteína ESAT-6 recombinante, purificada em condições nativa e desnaturante (Fig.3A e 3B), gerou reação cutânea média de 10,25 mm

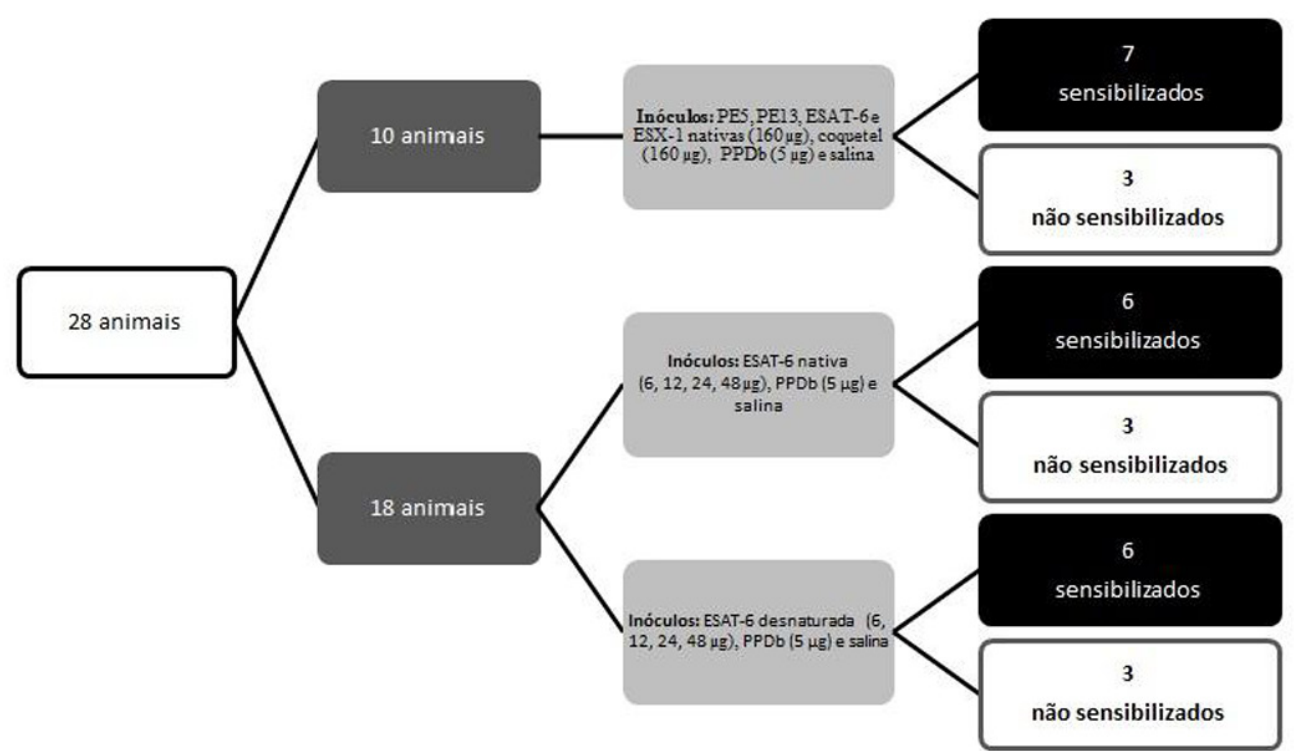

Fig.1. Fluxograma da distribuição dos animais (Cavia porcellus) nos grupos experimentais e os respectivos inóculos aplicados via intradérmica. 


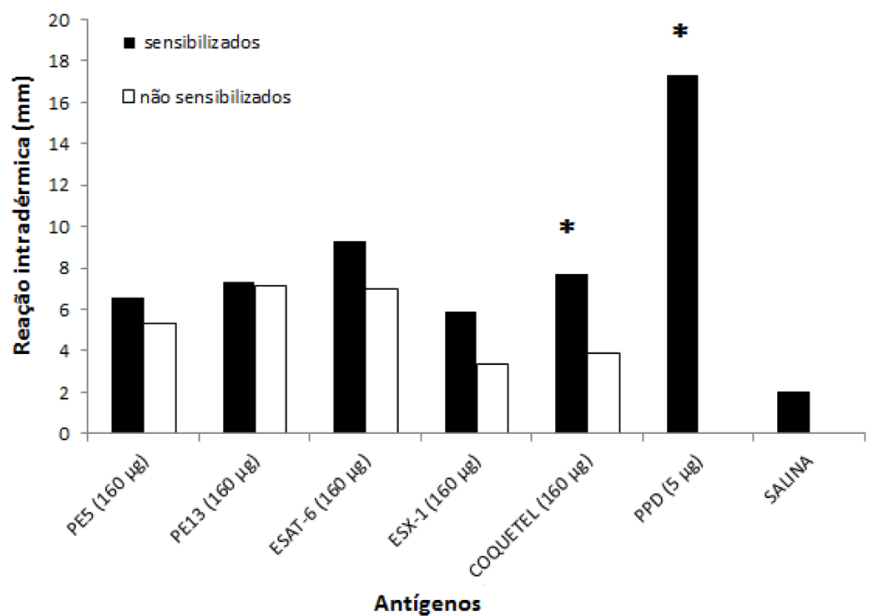

Fig.2. Tamanho médio das reações intradérmicas em Cavia porcellus sensibilizados e não sensibilizados com Mycobacterium bovis, utilizando as proteínas PE5, PE13, ESAT-6 e ESX-1 recombinantes purificadas em condições nativas $(160 \mu \mathrm{g})$ e coquetel $(40 \mu \mathrm{g}$ de cada). *Diferença significativa entre animais sensibilizados e não sensibilizados pelo teste $t$ de Student.

nos animais sensibilizados, em leitura realizada após 24 horas. Não houve diferença significativa $(p=0,063)$ entre a magnitude das reações induzidas pela proteína administrada nas dosagens de 6, 12, 24 e 48 $\mu$ g (Fig.4).

Os animais não sensibilizados também desenvolveram reação média de $10,25 \mathrm{~mm}$, mas somente em resposta as quatro dosagens testadas da proteína ESAT-6 purificada em condições desnaturantes, pois o mesmo não foi observado quando da utilização do PPD de M. bovis, salina e com as diferentes dosagens de ESAT-6 purificada em condição nativa.

A especificidade da proteína ESAT-6 em estimular reação cutânea nos animais foi influenciada pela condição de solubilização e purificação. Pois, ao comparar a utilização dos detergentes para solubilizar os agregados proteicos

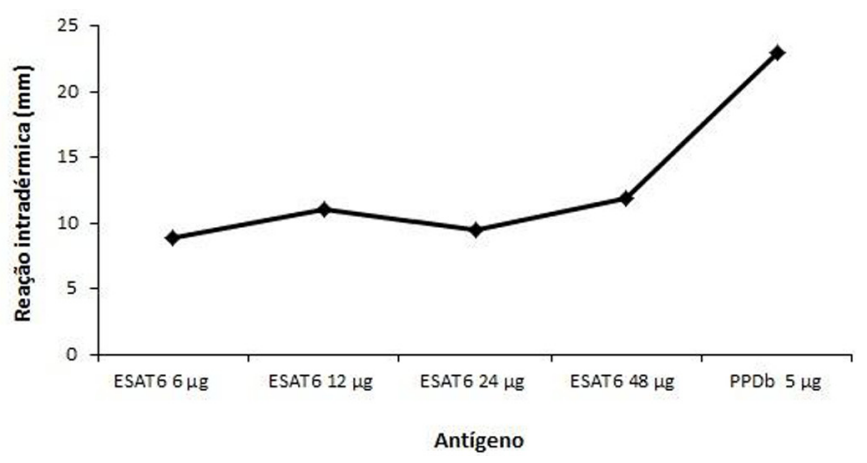

Fig.4. Comparação entre as reações intradérmicas médias (mm) desencadeadas pelas diferentes concentrações da proteína ESAT-6 (6, 12, 24, $48 \mu \mathrm{g})$ purificada em condições nativas quando aplicadas em teste intradérmico em Cavia porcellus sensibilizados com Mycobacterium bovis.

e purificação em condição nativa, em relação ao emprego de agente caotrópico para solubilização e purificação em condição desnaturante, foi observado que as proteínas que foram submetidas a esse último método induziram reações inflamatórias locais nos animais não sensibilizados, com as quatro dosagens de proteína testadas $(6,12,24$ e 48 $4 \mathrm{~g})$.

\section{DISCUSSÃO}

Estudos prévios têm demonstrado que a utilização de antígenos específicos do complexo Mycobacterium tuberculosis (CMT) em teste intradérmico pode proporcionar um diagnóstico mais específico e sensível (Whelan et al. 2010, Xin et al. 2013).

No presente estudo, avaliamos o potencial de ESAT-6 que é uma proteína naturalmente imunodominante entre as espécies do CMT (Mustafa et al. 2002), a ESX-1 e as proteínas da família das PEs, PE5 e PE13, que juntas são responsáveis pela interação com as células do hospedeiro, modulação da resposta imunológica e persistência da infecção (Sani et al. 2010).

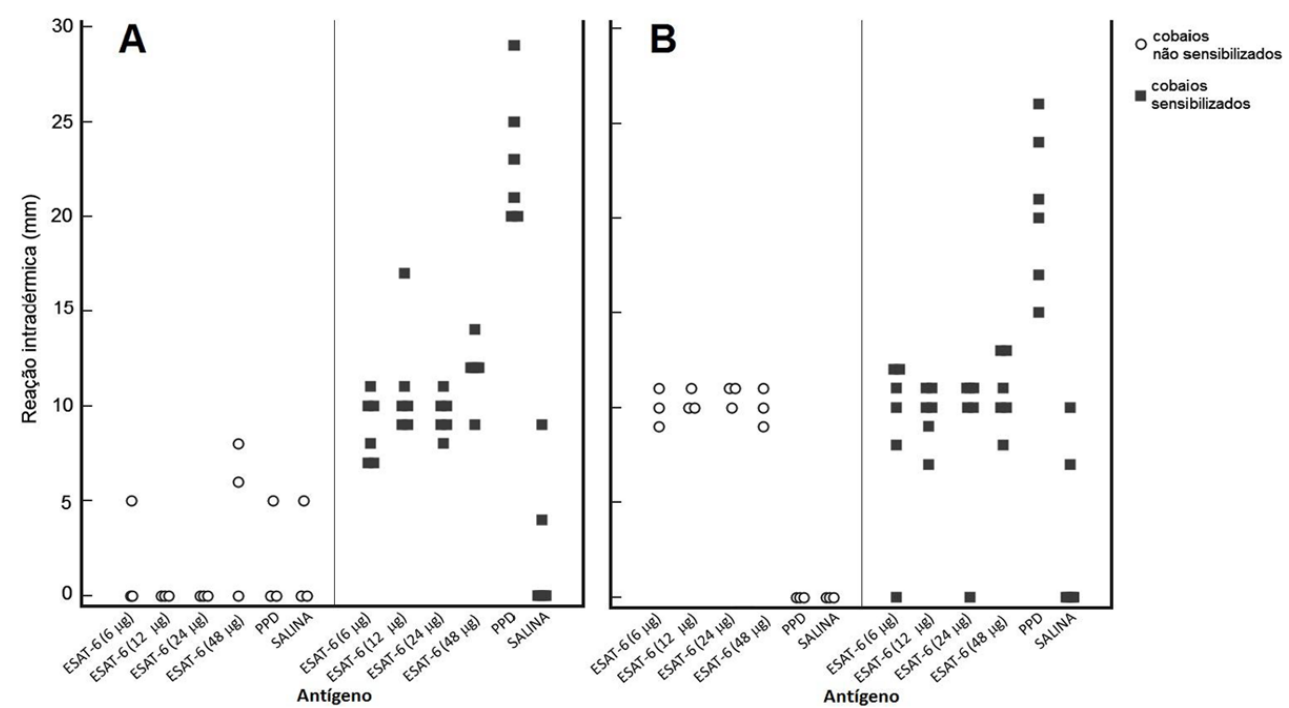

Fig.3. Comparação do desempenho da proteína ESAT-6 submetida a duas condições de purificação em estimular reação no teste intradérmico. (A) Proteína purificada em condições nativas; (B) Proteína purificada em condições desnaturantes. 
A aplicação desses antígenos tem variado e os resultados mais promissores têm sido observados quando combinações de antígenos em coquetéis são utilizadas em comparação com o PPD bovino (Whelan et al. 2010, Jones et al. 2012, Flores-Villalva et al. 2012). Assim como nesse estudo, em que o coquetel com as proteínas PE5, PE13, ESAT-6 e ESX-1 foi capaz de induzir resposta inflamatória nos animais sensibilizados, superiores as desencadeadas nos animais não sensibilizados. 0 que não pôde ser observado quando as mesmas proteínas foram aplicadas individualmente.

Em avaliação semelhante, utilizando as proteínas ESAT6, CFP10, MPB70, MPB83 e Rv3615c para teste intradérmico em bovinos, Whelan et al. (2010) observaram que as proteínas MPB70, MPB83 e RV3615c testadas isoladamente apresentaram pouca capacidade de induzir a produção de interferon-gama in vitro, se comparado com ESAT-6 e CFP10, assim como não foram capazes de detectar bovinos naturalmente infectados em teste intradérmico. A combinação dessas proteínas por outro lado, foi capaz de diferenciar animais infectados de não infectados no teste intradérmico. No entanto, a exclusão destas proteínas do coquetel diminuiu significativamente a sensibilidade do teste. 0 que indica que as proteínas subdominantes estão envolvidas no processo de hipersensibilidade tardia induzindo o recrutamento de células $\mathrm{T}$ antígeno-específicas que potencializam a ação das proteínas imunodominantes ESAT-6 e CFP10. 0 que leva a concluir que todos os antígenos desempenham papel fundamental na resposta contra $M$. bovis e consequentemente são importantes para serem testados no teste intradérmico.

Assim, considerando a importância da interação proteína-proteína e a interferência imunológica entre os vários componentes de coquetéis multiantigênicos, as reações de hipersensibilidade tardia devem ser investigadas usando várias combinações de proteínas em comparação com o PPD bovino (Kalra et al. 2010).

A proteína ESAT-6 confirmou seu potencial para o diagnóstico da tuberculose bovina, devido à capacidade demonstrada nesse estudo, quando purificada em condição nativa, em diferenciar os animais sensibilizados experimentalmente daqueles não sensibilizados, mesmo quando utilizada a menor concentração de $6 \mu \mathrm{g}$. Além disso, os resultados demonstraram não haver diferença significativa na magnitude das reações estimuladas por ESAT-6 nas do-

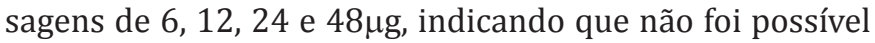
observar uma relação de dose dependência, assim como observado por Xin et al. (2013), ao testar as concentrações de 20, 50 e $70 \mu \mathrm{g}$ de ESAT- 6 juntamente com CFP10 e TB10.4 em teste intradérmico em bovinos. Por outro lado, Aggerbeck \& Madsen (2006) ao avaliarem ESAT-6 recombinante em teste cutâneo em animais, observaram uma reação proporcional ao aumento da concentração das proteínas de 0,01, 0,1 e $1 \mu \mathrm{g}$, mas que só foi verificado após sucessivas aplicações de seis doses da proteína no mesmo animal, o que estimulou a potencialização da resposta de hipersensibilidade.

As reações observadas nos animais não sensibilizados, induzidas pelas proteínas, podem estar relacionadas a subprodutos do processo de lise para ruptura da célula bac- teriana e liberação das proteínas e do método de solubilização e purificação das proteínas recombinantes, que são expressas na maioria das vezes na forma de corpúsculos de inclusão. Esses corpúsculos são compostos por agregados proteicos, geralmente na forma inativa e insolúvel, que se acumulam no interior da bactéria produtora, devido ao estresse por elevadas temperaturas ou superexpressão gênica (Singh \& Panda 2005). Além desses agregados homólogos, podem ser formados também agregados heterólogos de proteínas com lipídeos, polissacarídeos e com outros componentes de membrana (Fifis et al. 1994).

As proteínas produzidas nessas condições não podem ser purificadas de forma eficiente diretamente do cultivo celular, sem antes receberem um tratamento para a lise celular e solubilização dos agregados. Para esse procedimento, além das técnicas de lise mecânica como a desrupção ultrassônica e método físico como o choque térmico (congelamento/ descongelamento), é necessário lançar mão do processo de lise química utilizando agentes caotrópicos como a uréia e o hidrocloreto de guanidina que rompem as interações não covalentes, aumentam a solubilidade das substâncias apolares e desfazem as interações hidrofóbicas desnaturando as proteínas. No entanto, se levarmos em consideração que a imunotoxicidade é a questão mais importante à cerca dos reagentes utilizados para o diagnóstico intradérmico que depende de uma resposta imunológica (Du et al. 2013), esses agentes desnaturantes precisam ser totalmente removidos das amostras proteicas por apresentarem toxicidade celular. Contudo, o processo de diálise de $72 \mathrm{~h}$ empregado nesse estudo parece não ter sido suficiente para completa remoção desses reagentes das amostras proteicas.

Uma alternativa para solubilizar os corpúsculos de inclusão é a utilização dos surfactantes, como o sarcosil que é um detergente iônico e o triton X-100 um detergente não iônico que solubilizam os agregados proteicos devido à formação de complexo proteína/detergente sob condições normalmente não-desnaturantes, preservando a forma biologicamente ativa da proteína (Bhairi \& Mohan 2007). Apesar de o triton $\mathrm{X}$ apresentar massa micelar média de $80.000 \mathrm{Da}$, que não permite sua remoção por diálise, a sua utilização em baixa concentração (1\%), que foi adicionada no início do processo de purificação, somada as baixas concentrações de proteína $(6,12,24$ e $48 \mu \mathrm{g})$, se mostrou atóxico no teste cutâneo nos animais, permitindo a indução de reações inflamatórias específicas pelas proteínas. Além disso, esse detergente ajuda a remover as endotoxinas provenientes da parede celular da bactéria Escherichia coli na qual as proteínas foram produzidas, pois elas podem ativar a resposta imune e interferir nas reações induzidas pelas proteínas de M. bovis. Dessa forma, pode-se destacar que a utilização da proteína ESAT-6 isoladamente em uma concentração maior $(160 \mu \mathrm{g})$, provocou reações semelhantes tanto nos animais sensibilizados experimentalmente quanto nos não sensibilizados, o que indica que com o aumento da concentração da proteína, mais resíduos do detergente foi administrado no inóculo, o que levou a indução de reações inespecíficas.

Nesse sentido, Aggerbeck \& Madsen (2006) relatam que a rota de administração e a dose do antígeno influen- 
ciam a ocorrência de reações locais mesmo em animais não sensibilizados, pois observaram reações cutâneas de $6 \mathrm{~mm}$ em resposta a aplicação de $100 \mu \mathrm{g}$ da proteína ESAT-6 em animais naives, semelhante ao encontrado quando $1 \%$ de tween 20 foi injetado. Porém, quando $10 \mu \mathrm{g}$ de ESAT- 6 foi aplicada, não foram observadas reações nesses animais. Dessa forma, as reações inespecíficas desenvolvidas foram atribuídas aos resíduos do detergente tween 20 presente no tampão utilizado para a purificação da proteína.

\section{CONCLUSÕES}

As condições de solubilização e purificação influenciaram o desempenho antigênico das proteínas, pois, quando produzidas em condições desnaturantes desencadearam reações inespecíficas nos animais não sensibilizados, enquanto que aquelas produzidas em condições nativas e aplicadas na forma de um coquetel (PE5, PE13, ESAT-6 e ESX-1) na concentração de $40 \mu \mathrm{g}$ de cada proteína ou ESAT6 nativa aplicada individualmente nas concentrações $(6$, 12,24 e $48 \mu \mathrm{g}$ ) induziram reações intradérmicas significativas apenas em Cavia porcellus sensibilizados com Mycobacterium bovis inativado.

Tais respostas, embora presentes, ainda não fazem com que essas proteínas recombinantes representem uma alternativa ao teste intradérmico com PPD bovino.

Agradecimentos.- À Coordenação de Aperfeiçoamento de Pessoal de Nível Superior (CAPES), pela concessão de bolsa de doutorado, ao Laboratório Nacional Agropecuário (LANAGRO-SP) pelo fornecimento de Cavia porcellus, ao Conselho Nacional de Desenvolvimento Científico e Tecnológico (CNPq) e à Embrapa Gado de Corte pelo financiamento.

\section{REFERÊNCIAS}

Aggerbeck H. \& Madsen S.M. 2006. Safety of ESAT-6. Tuberculosis 86:363373.

Álvarez J., Perez A., Bezos J., Marqués S., Grau A., Saez J.L., Mínguez O., Juan L. \& Domínguez L. 2012. Evaluation of the sensitivity and specificity of bovine tuberculosis diagnostic tests in naturally infected cattle herds using a Bayesian approach. Vet. Microbiol. 155:38-43.

Bhairi S.M. \& Mohan C. 2007. Detergents: a guide to the properties and uses of detergents in biological systems. Calbiochem-Novabiochem Corporation. La Jolla. 42p.

Brasil 2006. Programa Nacional de Controle e Erradicação da Brucelose e da Tuberculose Animal (PNCEBT). - Departamento de Saúde Animal, Secretaria de Defesa Agropecuária, Ministério da Agricultura, Pecuária e Abastecimento (MAPA/SDA/DAS), Brasília. 188p.

Boland F., Kelly G.E., Good M. \& More S.J. 2010. Bovine tuberculosis and milk production in infected dairy herds in Ireland. Prev. Vet. Med. 93:153-161.

Buddle B.M., Livingstone P.G. \& Lisle G.W. 2009. Advances in ante-mortem diagnosis of tuberculosis in cattle. N. Z. Vet. J. 57:173-180.

Du W.X., Chen B.W., Lu J.B., Gao M.Q., Shen X.B., Yang L., Su C., Wang G.Z., Sun Q.F. \& Xu M. 2013. Preclinical study and phase I clinical safety evaluation of recombinant Mycobacterium tuberculosis ESAT-6 protein. Med. Sci. Monit. Basic Res. 19:146-152.
Fifis T., Rothel J.S. \& Wood P.R. 1994. Soluble Mycobacterium bovis protein antigens: Studies on their purification and immunological evaluation. Vet. Microbiol. 40:65-81.

Flores-Villalva S., Suárez-Güemes F., Espitia C., Whelan A.O., Vordermeier H.M. \& Gutiérrez-Pabello J.A. 2012. Tuberculin skin test specificity is modified by the use of a protein cocktail containing ESAT- 6 and CFP10 in Mycobacterium bovis naturally infected cattle. Clin. Vaccine Immunol. 19:797-803.

Jones G.J., Whelan A., Clifford D., Coad M. \& Vordermeier H.M. 2012. Improved skin test for differential diagnosis of bovine tuberculosis by the addition of Rv3020c-derived peptides. Clin. Vaccine Immunol. 19:620622.

Kalra M., Khuller G.K., Sheikh J.A. \& Verma I. 2010. Evaluation of Mycobacterium tuberculosis specific RD antigens for delayed type hypersensitivity responses in guinea pig. Indian J. Exp. Biol. 48:117-123.

Menin A., Fleith R., Reck C., Marlow M., Fernandes P., Pilati C. \& Báfica A. 2013. Asymptomatic cattle naturally infected with Mycobacterium bovis present exacerbated tissue pathology and bacterial dissemination. Plos One 8.

Michel A.L., Müller B. \& Van Helden P.D. 2010. Mycobacterium bovis at the animal-human interface: a problem, or not? Vet. Microbiol. 140:371381.

Mustafa A.S., Cockle P.J., Shaban F., Hewinson R.G. \& Vordermeier H.M. 2002. Immunogenicity of Mycobacterium tuberculosis RD1 region gene products in infected cattle. Clin. Exp. Immunol. 130:37-42.

OIE 2013. Bovine tuberculosis. Chapter 2.4.7. Manual of Diagnostic Tests and Vaccines for Terrestrial Animals. <http://www.oie.int/fileadmin/ Home/eng/Health_standards/tahm/2.04.07_BOVINE_TB.pdf> Acessado em 3 jun. 2013.

Sani M., Houben E.N.G., Geurtsen J., Pierson J., Punder K., Zon M.V., Wever B., Piersma S.R., Jiménez C.R., Daffé M., Appelmelk B.J., Bitter W., Van der Wel N. \& Peters P.J. 2010. Direct visualization by cryo-em of the mycobacterial capsular layer: a labile structure containing ESX-1-secreted proteins. Plos One 6.

Schiller I., Vordermeier H.M., Waters W.R., Whelan A.O., Coad M., Gormley E., Buddle B.M., Palmer M., Thacker T., McNair J., Welsh M., Hewinson R.G. \& Oesch B. 2010. Bovine tuberculosis: Effect of the tuberculin skin test on in vitro interferon gamma responses. Vet. Immunol. Immunopathol. 136:1-11.

Singh S.M. \& Panda A.K. 2005. Solubilization and refolding of bacterial inclusion body proteins. J. Biosci. Bioeng. 99:303-310.

Souza I.I.F., Melo E.S.P., Ramos C.A.N., Farias T.A., Osório A.L.A.R., Jorge K.S.G., Vidal C.E.S., Silva A.S., Silva M.R., Pellegrin A.O. \& Araújo F.R. 2012. Screening of recombinant proteins as antigens in indirect ELISA for diagnosis of bovine tuberculosis. SpringlerPlus 1:1-6.

Vutla J.B., Chandran D., Veerasami M., Sugumar P., Shahana P.V., Das D., Narasu M.L. \& Srinivasan V.A. 2011. Cloning, expression and purification of ESAT- 6 and CFP10 and their use in the detection of IFN- $\gamma$ responses in tuberculosis infected cattle. Biotechnol. Bioinformat. Bioeng. 1:255264.

Xin T., Jia H., Ding J., Li P., Yang H., Hou S., Yuan W., Guo X., Wang H., Liang Q., Li M., Wang B. \& Zhu H. 2013. Assessment of a protein cocktail-based skin test for bovine tuberculosis in a double-blind field test in cattle. Clin. Vaccine Immunol. 20:482-490.

Whelan A.O., Clifford D., Upadhyay B., Breadon E.L., McNair J., Hewinson G.R. \& Vordermeier M.H. 2010. Development of a skin test for bovine tuberculosis for differentiating infected from vaccinate animals. J. Clin. Microbiol. 48:3176-3181. 